\title{
A Cross-Sectional Study on Malnutrition in Inflammatory Bowel Disease: Is There a Difference Based on Pediatric or Adult Age Grouping?
}

\author{
Valérie Marcil, $R D, P h D,{ }^{*}{ }^{+}$Emile Levy, MD, $P h D,{ }^{+}$Devendra Amre, $M D, P h D,{ }^{\neq}$Alain Bitton, $M D,{ }^{*}$ \\ Ana Maria Guilhon de Araújo Sant'Anna, MD, ${ }^{*}$ Andrew Szilagy, $M D,{ }^{*}$ Daniel Sinnett, $P h D,{ }^{*}$ and \\ Ernest G. Seidman, MD*
}

Background: Malnutrition, commonly observed in inflammatory bowel disease (IBD), is associated with increased morbidity and mortality and is attributed to multiple causes. The added energy costs of growth in the child and adolescent with IBD are an additional risk factor.

Methods: The aim of the study was to perform a cross-sectional comparison of nutritional parameters in IBD between pediatric and adult cases. Results: We found that prevalence of undernutrition (low body mass index) and hypoalbuminemia was not different in pediatric, compared with adult patients. Anemia and iron deficiency were more often observed in pediatric subjects, compared with adults $(59.1 \%$ vs $36.9 \%$, respectively, $P<0.0001$; and $37.9 \%$ vs $25.3 \%, P<0.002)$. Vitamin $\mathrm{B}_{12}$ deficiency was significantly less common in the pediatric than in the adult group (5.4\% vs $19.4 \%, P<0.0001)$. Elevated C-reactive protein was more frequent in pediatric compared with adult cases $(49.8 \%$ vs $38.4 \%, P<0.01)$.

Conclusions: Patients with active Crohn's disease were more likely to be undernourished in both pediatric and adult populations. In both groups, predicators of undernutrition included low albumin levels (odds ratio [OR], 2.53; $P<0.006)$ and active disease (OR, 1.99; $P<0.03$ ). Our results call for close surveillance of nutritional status for IBD patients, regardless of age.

Key Words: inflammatory bowel disease, malnutrition, anemia, Crohn's disease, ulcerative colitis

\section{INTRODUCTION}

Received for publications August 13, 2018; Editorial Decision December 17, 2018

From the *IBD Research Group, McGill University Health Center, Montreal, Quebec, Canada; Research Centre, Sainte-Justine UHC, Departments of Nutrition and ${ }^{\ddagger}$ Pediatrics, Université de Montréal, Montreal, Quebec, Canada

Conflicts of interest: The authors declare that they have no competing interests.

Supported by: This study was supported in part by a Canadian Institutes of Health Research Team Grant (CTP-82942; E.G.S., E.L.) and the McGill IBD Research Group. Salary support was provided by the J.A. DeSève Research Chair in Nutrition (E.L.), the Canada Research Chair in Immune Mediated Gastrointestinal Disorders (E.G.S.), the Bruce Kaufman Endowed Chair in IBD at McGill (E.G.S.), a Canadian Institutes of Health Research Fellowship Award, and The Richard and Edith Strauss Postdoctoral Fellowships Award in Medicine, McGill University (V.M.).

Author contributions: V.M. was involved in the study concept and design, acquisition of data, analysis and interpretation of data, drafting of the manuscript, technical support, statistical analysis, and study supervision; E.G.S. contributed to the study concept and design, acquisition of data, analysis, interpretation of data, and study supervision; E.L., D.A., A.B., A.M.S., A.S., D.S., and E.G.S. contributed to critical revision of the manuscript for important intellectual content, administrative support, technical support, material support, study supervision, and obtaining funding; D.S. (both) and F.B. were involved in the study concept, acquisition, and analysis of data. All the authors have approved the final draft submitted.

Address correspondence to: Ernest Seidman, MD, Center for IBD Research, Research Institute of the McGill University Health Center, MGH Campus, 1650 Cedar Avenue, \#C10.145, Montreal, Quebec, Canada, H3G 1A4 (ernest.seidman@, mcgill.ca)

(C) 2019 Crohn's \& Colitis Foundation. Published by Oxford University Press. All rights reserved. For permissions, please e-mail: journals.permissions@oup.com. doi: 10.1093/ibd/izy403

Published online 22 February 2019
Inflammatory bowel diseases (IBDs), comprising Crohn's disease (CD), ulcerative colitis (UC), and unclassified colitis (IBDU), are chronic relapsing-remitting, immune-mediated disorders of the gastrointestinal tract. Malnutrition is observed in patients with IBD and is associated with increased morbidity and mortality. ${ }^{1}$ It has been reported that malnutrition is present in up to $85 \%$ of patients with IBD and that weight loss occurs in up to $80 \%$ of CD patients and $18 \%-62 \%$ of UC patients. ${ }^{2}$ In $\mathrm{CD}$, the prevalence and degree of malnutrition are influenced by the extent and severity of the disease. ${ }^{3}$ Although it has been often reported that patients with $\mathrm{CD}$ are at higher risk of malnutrition than those with UC, other studies have demonstrated that nutritional deficits occur to a similar degree. ${ }^{4}$

The most important factor associated with malnutrition in IBD is inadequate dietary intake, which can be secondary to avoidance due to exacerbation of symptoms when eating, exclusion of certain foods, or an impaired sense of taste., ${ }^{4}$ Excessive levels of inflammatory mediators, such as tumor necrosis factor- $\alpha$, interleukin- 1 , and interleukin- 6 , increase catabolism and lead to anorexia. ${ }^{6}$ Malnutrition in IBD can also be the result of increased energy requirements, ${ }^{7}$ malabsorption of nutrients, gastrointestinal losses, ${ }^{8}$ dietary intake, ${ }^{9}$ food avoidance, ${ }^{5,10}$ and drug-nutrient interactions. ${ }^{11}$

One of the most common complications of IBD is anemia, with a prevalence of up to $74 \%,{ }^{12}$ often due to the combination of iron $(\mathrm{Fe})$ deficiency and anemia from chronic 
disease. In some cases, anemia can be drug-induced (mesalazine, sulfasalazine, thiopurines) or due to folate or vitamin $B_{12}$ deficiency. Fe deficiency in IBD is primarily caused by chronic gastrointestinal tract blood loss. However, decreased absorption may also play a role in patients with active $\mathrm{CD}$ involving the proximal small bowel. ${ }^{13}$ The prevalence of Fe deficiency ranges from $36 \%$ to $90 \%$, depending on the criteria used for the definition and cohort selection. ${ }^{14,15}$

Inflammatory bowel disease patients may also present a variety of vitamin deficiencies as a consequence of the disease per se or of reduced dietary intake. ${ }^{16,17}$ Vitamin $B_{12}$ and folate deficiency are also relatively common in $\mathrm{CD}$, especially in patients with active disease. ${ }^{18}$ This can be caused by malabsorption or surgery, low-fiber diets, or antifolate drugs such as methotrexate and sulfasalazine. ${ }^{18,19}$ Cobalamin deficiency is more common in $\mathrm{CD}$ patients who have undergone ileal resections of $20 \mathrm{~cm}$ or more. ${ }^{20}$

Malnutrition may have serious consequences for IBD patients. Calorie-protein malnutrition is associated with impaired humoral and cellular immunity, which adversely affects the mucosal barrier. It has also been associated with deterioration in muscle and respiratory and immune functions, delayed wound healing, and postoperative complications. ${ }^{21}$ The added energy costs of growth in the child and adolescent with IBD are an additional risk factor. Weight loss is present at diagnosis in up to $90 \%$ of children, ${ }^{22}$ and growth failure is one of the most frequent extraintestinal manifestations seen in pediatric-onset disease. ${ }^{23}$ Indeed, growth retardation at diagnosis has been reported in $23 \%-88 \%$ of $\mathrm{CD}$ children and may precede the gastrointestinal manifestations by years. ${ }^{24}$

Several studies have evaluated nutritional status in IBD patients, but few have compared malnutrition between children and adults. The aim of this study was to perform a comparative analysis of nutritional parameters between pediatric and adult patients with IBD.

\section{METHODS}

\section{Patient Cohorts}

We performed a cross-sectional comparison of nutritional status in pediatric and adult patients with IBD, grouped as $\mathrm{CD}$, UC, or IBDU, according to the Montreal classification. ${ }^{25}$ Subjects aged 16 years and under were classified as pediatric IBD. ${ }^{25}$ In cases where the age of a subject overlapped the 2 categories over different visits, the average age was used to classify the patient as pediatric or adult. Patients were recruited from the 4 principal tertiary medical centers of the McGill Faculty of Medicine (Montreal Children's Hospital, Montreal General Hospital, Royal Victoria Hospital, Jewish General Hospital) over a 2-year period (2008-2010). Clinical and biochemical parameters at each visit were collected using the McGill IBD database. Parameters surveyed included body mass index (BMI), hemoglobin $(\mathrm{Hb})$, serum $\mathrm{Fe}$, vitamin $\mathrm{B}_{12}$, folate, albumin, and C-reactive protein (CRP). The average BMI of each visit was calculated. Disease activity was determined at each clinical visit by the Harvey-Bradshaw Index (HBI) for $\mathrm{CD}^{26}$ or the Lichtiger Index (LI) for UC and IBDU. ${ }^{27}$ The disease was considered active when the HBI was $>4$ or the LI was $>2$. Data on medications taken and usage of enteral nutritional therapy, nutritional supplements, and vitamins were also collected.

\section{Assessment of Undernutrition and Height Deficit}

Body mass index was assessed at each visit as weight $(\mathrm{kg})$ divided by squared height $\left(\mathrm{m}^{2}\right)$. Severe undernutrition was defined based on World Health Organization (WHO) criteria: $\mathrm{BMI} z$-score for age $>2$ SDs below the mean in patients $<20$ years of age, ${ }^{28}$ or a BMI $<18.5$ in adults age $20-64$ years, ${ }^{28}$ and a BMI $<20$ in adults $>65 .{ }^{29}$ Mild undernutrition was defined by BMI $z$-score for age $<1.5 \mathrm{SDs}$ in patients $<20$ years of age, ${ }^{28}$ or a BMI $<19.5$ in adults age $20-64$ years, ${ }^{30}$ and a BMI $<22$ in adults $>65 .{ }^{29}$ Patients meeting these criteria at a minimum of 1 visit during their follow-up were classified with severe or mild undernutrition.

In parallel, we determined the height deficit of children by computing the z-scores for height-for-age ( 5 to 19 years old) and for weight-for-height ( $<5$ years old) using the WHO charts. ${ }^{28}$ Growth was classified as normal (>1.5 SDs), with moderate deficit ( $\leq 1.5$ SDs and $>2$ SDs), and severe deficit $(\leq 2$ SDs). Children with abnormal criteria at a minimum of 1 visit during their follow-up visit were classified as having moderate or severe growth retardation.

\section{Assessment of Nutritional Status Using Biochemical Parameters}

Abnormal micronutrient status was defined by ageadjusted values below normal cutoffs. Levels of serum albumin, $\mathrm{Hb}, \mathrm{Fe}$, vitamin $\mathrm{B}_{12}$, folate, and $\mathrm{CRP}$ were determined at each visit. Hypoalbuminemia was defined according to age: $0-1$ year: $<30 \mathrm{~g} / \mathrm{L} ; 1-10$ years: $<39 \mathrm{~g} / \mathrm{L}$; $10-18$ years: $<41 \mathrm{~g} / \mathrm{L} ; 18$ y and over: $<38 \mathrm{~g} / \mathrm{L} .{ }^{4,31} \mathrm{Hb}$ levels were evaluated according to age and sex. The following cutoff values were used: $1-5$ years: $<110 \mathrm{~g} / \mathrm{L} ; 6-12$ years: $<120$ g/L; male $12-17$ years: $<130 \mathrm{~g} / \mathrm{L}$; female $12-17$ years: $<120 \mathrm{~g} / \mathrm{L}$; male 18 and over: $<140 \mathrm{~g} / \mathrm{L}$; female 18 and over: $<120 \mathrm{~g} / \mathrm{L} .{ }^{32}$ For all subjects, serum $\mathrm{Fe}$ concentrations were classified as low when $<10 \mu \mathrm{mol} / \mathrm{L} .{ }^{33}$ Vitamin $\mathrm{B}_{12}$ levels $<148$ $\mathrm{pmol} / \mathrm{L}^{34}$ and/or the need for ongoing $\mathrm{B}_{12}$ supplementation indicated $\mathrm{B}_{12}$ deficiency. Folate levels were characterized as low when inferior to $7 \mathrm{nmol} / \mathrm{L}$ in serum, or $317 \mathrm{nmol} / \mathrm{L}$ in red blood cells. ${ }^{35,}{ }^{36}$ CRP levels were elevated when $>5 \mathrm{mg} / \mathrm{L}$ in children ${ }^{37}$ and $>10 \mathrm{mg} / \mathrm{L}$ in adults. ${ }^{38}$ Patients meeting these criteria at a minimum of 1 visit during their follow-up were classified as having abnormal levels of the specific biochemical parameter. 


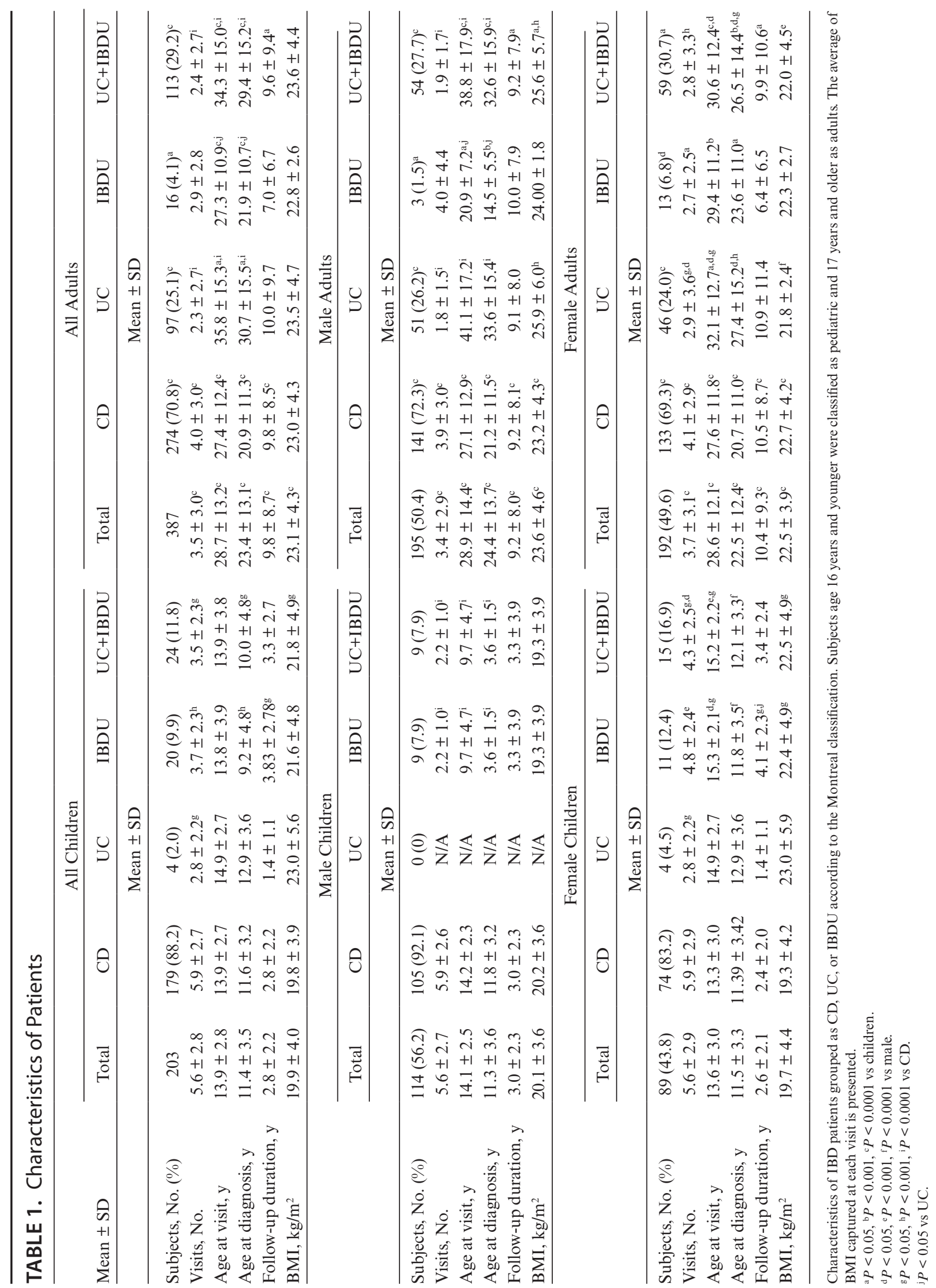




\section{Measurement of Antioxidant Vitamins}

To examine the levels of plasma antioxidant vitamins (retinol, $\beta$-carotene, $\alpha$-tocopherol, and $\gamma$-tocopherol), blood samples were collected in tubes containing $1 \mathrm{~g}$ EDTA/L. Plasma was separated immediately by centrifugation $(700 \mathrm{~g}$ for 20 minutes at $4^{\circ} \mathrm{C}$ ), and the vitamin levels of $48 \mathrm{CD}$ adult patients were determined using an improved method previously described by our team. ${ }^{39}$

\section{Essential Fatty Acid Deficiency}

To detect essential fatty acid (EFA) deficiencies in 48 adult $\mathrm{CD}$ patients, blood samples were collected in tubes containing $1 \mathrm{~g}$ EDTA/L, and plasma was separated immediately by centrifugation ( $700 \mathrm{~g}$ for 20 minutes at $4^{\circ} \mathrm{C}$ ). For trans-esterification, an internal standard consisting of $14.952 \mu \mathrm{g}$ of nonadecenoic acid (C19:1) was precisely weighed, dissolved in $2 \mathrm{~mL}$ of methanol-hexane (4:1, v:v), and mixed with $100 \mu \mathrm{L}$ of cell homogenate. Then $200 \mu \mathrm{L}$ of acetyl chloride was added, and each tube was subjected to methanolysis at $100^{\circ} \mathrm{C}$ for 1 hour. After tubes had been cooled, $5 \mathrm{~mL}$ of $6 \% \mathrm{~K}_{2} \mathrm{CO}_{3}$ solution was added to stop the reaction and neutralize the mixture. The tubes were then shaken and centrifuged, and an aliquot of the hexane upper phase was injected into the chromatograph, as previously described, ${ }^{40}$ using the Varian 8400 GC Autosampler system (Cole-Parmer, Vernon Hills, IL). The fatty acids were identified by comparison with the expected retention times of known standards and were analyzed with Galaxie Chromatography Data System software (Varian Inc., Palo Alto, CA, USA). To assess EFA status, we used the

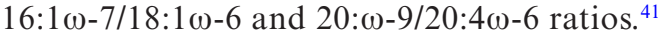

\section{Statistical Analysis}

We used Prism 5 for Mac OS X (GraphPad Software, Inc, La Jolla, CA, USA) and SPSS (version 24, IBM Analytics, Armonk, NY, USA) for the statistical analyses. Results were considered statistically different at $P<0.05$. Data are expressed as mean $\pm \mathrm{SD}$, median, prevalence (No.), or percentage. For patients' descriptive characteristics (continuous variables), differences in means between groups were assessed using the Mann-Whitney $t$ test. Differences in the prevalence of undernutrition and abnormal biochemical parameters assessing nutritional status between groups (categorical variables) were analyzed using the chi-square $\left(\chi^{2}\right)$ test. If criteria for the use of the $\chi^{2}$ test were not met, the Fisher exact test was used. Comparisons were made between the pediatric and adult cohorts, and, in each subgroup, between $\mathrm{CD}$, UC, and IBDU, and between males and females. To determine predictors of undernutrition in $\mathrm{CD}$, we used a logistic regression model including all variables. Odds ratios (ORs) and corresponding 95\% confidence intervals $(95 \% \mathrm{CIs})$ were estimated.

\section{Ethical Considerations}

Consent was obtained from the participants, and the ethics committee of the McGill University Health Center approved the study.

\section{RESULTS}

\section{Characteristics of Patients}

In total, 590 patients with IBD (203 pediatric and 387 adult) were evaluated over the study period. The cohort was composed of patients seen for follow-up outpatient visits. Descriptive characteristics are presented in Table 1. The mean age at visit was $13.9 \pm 2.8$ years and $28.7 \pm 13.2$ years for pediatric and adult cases, respectively. Overall, there was no difference in the proportion of males and females in the pediatric and adult cohorts. Because patients were grouped according to their mean age at visit over the study period, some started the study as pediatric subjects but were, in the end, classified as adults. A total of 11 men (all CD) and 14 women (13 CD and 1 IBDU) overlapped the 2 categories.

Crohn's disease was the most prevalent form of IBD in both age groups ( $88.2 \%$ in pediatric and $70.8 \%$ in adults). In adults, IBDU was less frequent $(4.1 \%$ vs $9.8 \%, P<0.01)$ and UC was more common $(25.1 \%$ vs $2.0 \%, P<0.0001)$. In the adult group, the prevalence of IBDU was lower among males compared with females $(1.5 \%$ vs $6.8 \%, P<0.01)$. The mean number of visits was greater in the pediatric compared with the adult population $(5.6 \pm 2.8$ vs $3.5 \pm 3.0, P<0.0001)$ and in the CD compared with the UC group (in children: $5.9 \pm 2.7$ vs $2.8 \pm 2.2, P<0.02$; in adults: $4.0 \pm 2.9$ vs $2.3 \pm 2.7, P<0.0001$ ). Age at diagnosis was significantly lower in adults with $\mathrm{CD}$ than with $\mathrm{UC}(20.9 \pm 11.3$ vs $30.7 \pm 15.5$ years, $P<0.0001)$, both in males and females. As expected, the duration of follow-up was shorter in pediatric compared with adult patients ( $2.8 \pm 2.2$ vs $9.8 \pm 8.7$ years, $P<0.0001)$. In both pediatric and adult cohorts, there was no significant difference in BMI between males and females, or between CD, UC, and IBDU. However, the average BMI was lower in children than in adults $(19.9 \pm 4.0$ vs $23.1 \pm 4.3, P<0.0001)$ (Table 1$)$.

The population was mainly of Caucasian origin $(65.8 \%)$, followed by Jewish Ashkenazi (19.0\%), Middle Eastern (4.6\%), Asian (3.9\%), African American (3.0\%), Jewish Sepharadic $(2.7 \%)$, Latin American $(0.8 \%)$, and mixed $(0.2 \%)$. In the pediatric cohort, 37 cases $(18.2 \%)$ were included in the database at the time of diagnosis (16 boys, $14.0 \%$; 21 girls, 23.6\%). Most of them had a diagnosis of CD (16 boys, $100 \% ; 19$ girls, 90.4\%), 1 girl was diagnosed with UC (4.8\%), and another had IBDU (4.8\%). The proportion of newly diagnosed adults was significantly lower: only 10 patients $(2.6 \%, P<0.0001$ vs children; 4 men, $2.1 \%$; 6 women, $3.1 \%$ ) were included in the database at the time of first visit. This included $6 \mathrm{CD}(2.2 \% ; 2$ men, $1.4 \%$; 
4 women, 3.0\%), 2 UC (2 men, 3.9\%), and 2 IBDU patients (2 women, $3.4 \%$ ).

In keeping with the Montreal Classification, subjects age 16 years and under were classified as pediatric and those 17 and over as adult IBD. However, to elucidate the influence of age classifications on results, all analyses were repeated using 18 years as the cutoff for the pediatric age group. The results obtained from this additional analysis did not yield to significantly different findings from the primary analysis.

\section{Prevalence of Undernutrition Based on BMI in Children and Adults}

The data on prevalence of undernutrition, based on BMI, for pediatric and adult IBD cohorts are illustrated in Table 2. The overall prevalence of undernutrition was similar in pediatric compared with adult patients ( $14.3 \%$ vs $13.7 \%$ ), as was the proportion of cases with severe or mild undernutrition. There was a trend toward a higher proportion of mild undernutrition in female pediatric cases compared with female adult cases $(12.4 \%$ vs $5.7 \%, P<0.06)$ and compared with male children $(P<0.06)$. We did not observe differences in the prevalence of undernutrition between the $\mathrm{CD}, \mathrm{UC}$, and IBDU groups. The prevalence of severe undernutrition, defined according to
WHO criteria, was similar between the 2 age groups $(6.4 \%$ in children and 9.0\% in adults).

We carried out further analyses to determine if undernutrition was associated with disease activity. Subjects with active $\mathrm{CD}$ were more likely to be undernourished, in both the pediatric $(26.3 \%$ vs $11.5 \%$ with inactive disease, $P<0.016)$ and adult $(21.2 \%$ vs $11.8 \%$ with inactive disease, $P<0.043)$ cohorts. This was also observed in adult UC $(22.2 \%$ of those with active disease vs $5.7 \%$ with inactive disease, $P<0.026$ ), but the low number of pediatric UC cases does not allow for drawing conclusions in children. When analyses were performed separately for sex, the significant relationship between disease activity and undernutrition was maintained in female children and in male adults.

In $\mathrm{CD}, 87$ children (48.6\%) and 155 adults (56.6\%) were receiving treatment with a biological and/or steroid at the time of a visit. The proportion of patients on a steroid alone or both steroid and a biological was not different between children and adults (31.3\% vs $26.3 \%$ and $13.4 \%$ vs $17.1 \%$, respectively). However, the proportion of children treated only with a biological was significantly lower than adults $(3.9 \%$ vs $13.1 \%$, $P<0.0009$ ). Overall, the number of patients treated with enteral nutrition was low and only comprised of $\mathrm{CD}$ patients (children: 2 boys and 1 girl; adults: 2 men)

TABLE 2. Prevalence of Undernutrition According to BMI

\begin{tabular}{|c|c|c|c|c|c|c|c|c|c|c|}
\hline \multirow[b]{3}{*}{ Degree of Undernutrition } & \multicolumn{5}{|c|}{ All Children, No. (\%) } & \multicolumn{5}{|c|}{ All Adults, No. $(\%)$} \\
\hline & Total & $\mathrm{CD}$ & $\mathrm{UC}$ & IBDU & $\mathrm{UC}+\mathrm{IBDU}$ & Total & CD & $\mathrm{UC}$ & IBDU & $\mathrm{UC}+\mathrm{IBDU}$ \\
\hline & $(\mathrm{n}=203)$ & $(n=179)$ & $(n=4)$ & $(\mathrm{n}=20)$ & $(\mathrm{n}=24)$ & $(\mathrm{n}=387)$ & $(n=274)$ & $(\mathrm{n}=97)$ & $(\mathrm{n}=16)$ & $(\mathrm{n}=113)$ \\
\hline Severe & $13(6.4)$ & $13(7.3)$ & $0(0)$ & $0(0)$ & $0(0)$ & $35(9.0)$ & $25(9.1)$ & $8(8.3)$ & $2(12.5)$ & $10(8.9)$ \\
\hline Mild & $16(7.9)$ & $15(8.4)$ & $1(25.0)$ & $0(0)$ & $1(4.2)$ & $20(5.2)$ & $18(6.6)$ & $2(2.1)$ & $0(0)$ & $2(1.8)$ \\
\hline \multirow[t]{3}{*}{ Combined } & $29(14.3)$ & $28(15.6)$ & $1(25.0)$ & $0(0)$ & $1(4.2)$ & $53(13.7)$ & $41(15.0)$ & $10(10.3)$ & $2(12.5)$ & $12(10.6)$ \\
\hline & \multicolumn{5}{|c|}{ Male Children, No. (\%) } & \multicolumn{5}{|c|}{ Male Adults, No. $(\%)$} \\
\hline & Total & $\mathrm{CD}$ & $\mathrm{UC}$ & IBDU & $\mathrm{UC}+\mathrm{IBDU}$ & Total & CD & UC & IBDU & $\mathrm{UC}+\mathrm{IBDU}$ \\
\hline Degree of Undernutrition & $(n=114)$ & $(\mathrm{n}=105)$ & $(\mathrm{n}=0)$ & $(\mathrm{n}=9)$ & $(\mathrm{n}=9)$ & $(\mathrm{n}=195)$ & $(n=141)$ & $(\mathrm{n}=51)$ & $(\mathrm{n}=3)$ & $(\mathrm{n}=54)$ \\
\hline Severe & $8(7.0)$ & $8(7.6)$ & N/A & $0(0)$ & $0(0)$ & $16(8.2)$ & $13(9.2)$ & $3(5.9)$ & $0(0)$ & $3(5.6)$ \\
\hline Mild & $5(4.4)$ & $5(4.8)$ & N/A & $0(0)$ & $0(0)$ & $9(4.6)$ & $9(6.4)$ & $0(0)$ & $0(0)$ & $0(0)$ \\
\hline \multirow[t]{3}{*}{ Combined } & $13(11.4)$ & $13(12.4)$ & N/A & $0(0)$ & $0(0)$ & $25(12.8)$ & $22(15.6)$ & $3(5.9)$ & $0(0)$ & $3(5.6)$ \\
\hline & \multicolumn{5}{|c|}{ Female Children, No. ( $\%)$} & \multicolumn{5}{|c|}{ Female Adults, No. (\%) } \\
\hline & Total & $\mathrm{CD}$ & $\mathrm{UC}$ & IBDU & $\mathrm{UC}+\mathrm{IBDU}$ & Total & CD & UC & IBDU & $\mathrm{UC}+\mathrm{IBDU}$ \\
\hline Degree of Undernutrition & $(\mathrm{n}=89)$ & $(\mathrm{n}=74)$ & $(n=4)$ & $(\mathrm{n}=11)$ & $(n=15)$ & $(n=192)$ & $(n=133)$ & $(n=46)$ & $(n=13)$ & $(\mathrm{n}=59)$ \\
\hline Severe & $5(5.6)$ & $5(6.8)$ & $0(0)$ & $0(0)$ & $0(0)$ & $19(9.9)$ & $12(9.0)$ & $5(10.9)$ & $2(15.4)$ & 7 (11.9) \\
\hline Mild & $11(12.4)^{\mathrm{b}}$ & $10(13.5)^{\mathrm{c}}$ & $1(25.0)$ & $0(0)$ & $1(6.7)$ & $11(5.7)^{\mathrm{a}}$ & $9(6.8)$ & $2(4.4)$ & $0(0)$ & $2(3.4)$ \\
\hline Combined & $16(18.0)$ & $15(20.3)$ & $1(25.0)$ & $0(0)$ & $1(6.7)$ & $30(15.6)$ & $21(15.8)$ & $7(15.2)$ & $2(15.4)$ & $9(15.3)$ \\
\hline
\end{tabular}

Prevalence of severe, mild, and total undernutrition in pediatric and adult cohorts.

${ }^{\text {a }} P<0.06$ vs children.

${ }^{\mathrm{b}} P<0.06,{ }^{\mathrm{c}} P<0.05$ vs male. 
TABLE 3. Medications in CD Patients According to Nutritional Status

\begin{tabular}{|c|c|c|c|c|}
\hline \multirow[b]{3}{*}{ Medication } & \multicolumn{2}{|c|}{ All CD Children, No. (\%) } & \multicolumn{2}{|c|}{ All CD Adults, No. (\%) } \\
\hline & \multicolumn{2}{|c|}{ Undernutrition } & \multicolumn{2}{|c|}{ Undernutrition } \\
\hline & No $(n=151)$ & Yes $(\mathrm{n}=28)$ & No $(n=233)$ & Yes $(n=41)$ \\
\hline Biologicals or steroids & $65(43.0)$ & $22(78.6)^{\mathrm{c}}$ & $133(57.1)$ & $22(53.7)^{\mathrm{a}}$ \\
\hline Biologicals & $6(4.0)$ & $1(3.6)$ & $35(15.0)$ & $1(2.4)$ \\
\hline Steroids+immunomodulators & $38(25.2)$ & $14(50.0)$ & $52(22.3)$ & $10(24.4)$ \\
\hline Steroids only & $4(2.7)$ & $0(0)$ & $7(3.0)$ & $3(7.3)$ \\
\hline \multirow[t]{3}{*}{ Biologicals+steroids } & $17(11.3)$ & $7(25.0)$ & $39(16.7)$ & $8(19.5)$ \\
\hline & \multicolumn{2}{|c|}{ Male CD Children, No. (\%) } & \multicolumn{2}{|c|}{ Male CD Adults, No. (\%) } \\
\hline & \multicolumn{2}{|c|}{ Undernutrition } & \multicolumn{2}{|c|}{ Undernutrition } \\
\hline Medication & No $(n=92)$ & Yes $(n=13)$ & No $(n=119)$ & Yes $(n=22)$ \\
\hline Biologicals or steroids & $42(45.6)$ & $9(69.2)$ & $61(51.2)$ & $14(63.6)$ \\
\hline Biologicals & $4(4.3)$ & $1(7.7)$ & $15(12.6)$ & $0(0)$ \\
\hline Steroids+immunomodulators & $25(27.2)$ & $4(30.8)$ & $21(17.6)$ & $8(36.4)$ \\
\hline Steroids only & $3(3.3)$ & $0(0)$ & $5(4.2)$ & $1(4.5)$ \\
\hline \multirow[t]{3}{*}{ Biologicals+steroids } & $10(10.9)$ & $4(30.8)$ & $20(16.8)$ & $5(22.7)$ \\
\hline & \multicolumn{2}{|c|}{ Female CD Children, No. $(\%)$} & \multicolumn{2}{|c|}{ Female CD Adults, No. (\%) } \\
\hline & \multicolumn{2}{|c|}{ Undernutrition } & \multicolumn{2}{|c|}{ Undernutrition } \\
\hline Medication & No $(n=59)$ & Yes $(n=15)$ & No $(n=112)$ & Yes $(\mathrm{n}=21)$ \\
\hline Biologicals or steroids & $23(39.0)$ & $13(86.7)$ & $72(64.3)$ & $8(38.1)^{\mathrm{b}}$ \\
\hline Biologicals & $2(3.4)$ & $0(0)$ & $20(17.9)$ & $1(4.8)$ \\
\hline Steroids+immunomodulators & $13(22.0)$ & $10(66.7)^{\mathrm{a}}$ & $31(27.7)$ & $2(9.5)^{b}$ \\
\hline Steroids only & $1(1.7)$ & $0(0)$ & $2(1.8)$ & $2(9.5)$ \\
\hline Biologicals+steroids & 7 (11.9) & $3(20.0)$ & $19(17.0)$ & $3(14.3)$ \\
\hline
\end{tabular}

Prevalence of $\mathrm{CD}$ patients on steroids and/or biological treatments according to their nutritional status. ${ }^{\mathrm{a}} P<0.05,{ }^{\mathrm{b}} P<0.01$ vs children.

${ }^{c} P<0.0008$ vs well-nourished.

As the usage of medication can affect BMI, undernutrition data were analyzed according to the administration of steroids and/or biologicals (Table 3). Undernourished CD children were more likely to be treated with biologicals and/or steroids than undernourished $\mathrm{CD}$ adults $(78.6 \%$ vs $53.7 \%, P<0.05)$. Among females with $\mathrm{CD}$, a larger proportion of children than adults were receiving steroid treatment ( $66.7 \%$ vs $19.0 \%, P<0.006)$. Interestingly, in children, the proportion of subjects on medication was higher in the undernourished group $(78.6 \%$ in undernourished vs $43.0 \%$ in well-nourished, $P<0.0008$ ), whereas the percentages of patients with and without undernutrition taking medication were similar in adults ( $57.1 \%$ vs $53.7 \%$ ). No significant differences were noted between males and females in both the pediatric and adult groups or in UC and IBDU (Supplementary Tables 1-3).

\section{Prevalence of Growth Retardation in Children}

We found that $14.3 \%$ of children presented with growth retardation (moderate and severe), which was the same prevalence as undernutrition. Although most patients had both conditions, $4.4 \%$ had either growth retardation or undernutrition. However, no statistical differences were observed between the prevalence of growth retardation and undernutrition when groups were analyzed according to sex and disease (data not shown).

\section{Biochemical Markers}

Data on biochemical markers of malnutrition are shown in Table 4. As seen for BMI, the prevalence of hypoalbuminemia was not different between the pediatric and adult IBD groups. The frequency of hypoalbuminemia was higher in $\mathrm{CD}$, compared with subjects with UC and IBDU, for both the pediatric and adult cohorts (in children: $30.7 \%$ vs $8.3 \%$, respectively, $P<0.05$; in adults: $29.2 \%$ vs $9.7 \%, P<0.0001$ ). In the adult group, men with UC were less likely to have low levels of serum albumin than women $(3.9 \%$ vs $17.4 \%, P<0.05)$.

Anemia was observed more frequently in pediatric compared with adult IBD patients ( $59.1 \%$ vs $36.9 \%, P<0.0001)$. 
TABLE 4. Prevalence of Abnormal Biochemical Parameters in Adult and Pediatric IBD

\begin{tabular}{|c|c|c|c|c|c|c|c|c|c|c|}
\hline & \multicolumn{5}{|c|}{ All Children, No. $(\%)$} & \multicolumn{5}{|c|}{ All Adults, No. (\%) } \\
\hline & Total & $\mathrm{CD}$ & $\mathrm{UC}$ & IBDU & $\mathrm{UC}+\mathrm{IBDU}$ & Total & $\mathrm{CD}$ & $\mathrm{UC}$ & IBDU & $\mathrm{UC}+\mathrm{IBDU}$ \\
\hline & $(\mathrm{n}=203)$ & $(n=179)$ & $(n=4)$ & $(\mathrm{n}=20)$ & $(\mathrm{n}=24)$ & $(\mathrm{n}=387)$ & $(\mathrm{n}=274)$ & $(\mathrm{n}=97)$ & $(n=16)$ & $(\mathrm{n}=113)$ \\
\hline Albumin & $57(28.1)$ & $55(30.7)$ & $0(0)$ & $2(10.0)$ & $2(8.3)^{\mathrm{e}}$ & $91(23.5)$ & $80(29.2)$ & $10(10.3)^{g}$ & $1(6.2)^{\mathrm{e}}$ & $11(9.7)^{\mathrm{g}}$ \\
\hline Hemoglobin & $120(59.1)$ & $109(60.9)$ & $3(75.0)$ & $8(40.0)$ & $11(45.8)$ & $143(37.0)^{\mathrm{c}}$ & $122(44.5)^{\mathrm{b}}$ & $18(18.6)^{\mathrm{a}, \mathrm{i}}$ & $3(18.8)$ & $21(18.6)^{\mathrm{a}, \mathrm{g}}$ \\
\hline Iron & 77 (37.9) & $72(40.2)$ & $0(0)$ & $5(25.0)$ & $5(20.8)$ & $98(25.3)^{\mathrm{a}}$ & $85(31.0)$ & $13(13.4)^{\mathrm{f}}$ & $0(0)$ & $13(11.5)^{g}$ \\
\hline B12 & $11(5.4)$ & $10(5.6)$ & $0(0)$ & $1(5.0)$ & $1(4.2)$ & $75(19.4)^{\mathrm{c}}$ & $72(26.3)^{\mathrm{c}}$ & $3(3.1)^{\mathrm{g}}$ & $0(0)^{\mathrm{e}}$ & $3(2.7)^{\mathrm{g}}$ \\
\hline Folate & $6(3.0)$ & $6(3.4)$ & $0(0)$ & $0(0)$ & $0(0)$ & $10(2.6)$ & $9(3.3)$ & $1(1.0)$ & $0(0)$ & $1(0.9)$ \\
\hline \multirow[t]{4}{*}{ CRP } & $101(49.8)$ & $99(55.3)$ & $0(0)$ & $2(10.0)^{\mathrm{f}}$ & $2(8.3)^{\mathrm{g}}$ & $149(38.5)^{\mathrm{a}}$ & $130(47.4)$ & $15(15.5)^{\mathrm{g}}$ & $4(25.0)$ & $19(16.8)^{\mathrm{g}}$ \\
\hline & \multicolumn{5}{|c|}{ Male Children, No. $(\%)$} & \multicolumn{5}{|c|}{ Male Adults, No. (\%) } \\
\hline & Total & $\mathrm{CD}$ & $\mathrm{UC}$ & IBDU & $\mathrm{UC}+\mathrm{IBDU}$ & Total & $\mathrm{CD}$ & $\mathrm{UC}$ & IBDU & $\mathrm{UC}+\mathrm{IBDU}$ \\
\hline & $(\mathrm{n}=114)$ & $(\mathrm{n}=105)$ & $(\mathrm{n}=0)$ & $(\mathrm{n}=9)$ & $(\mathrm{n}=9)$ & $(\mathrm{n}=195)$ & $(\mathrm{n}=141)$ & $(\mathrm{n}=51)$ & $(n=3)$ & $(\mathrm{n}=54)$ \\
\hline Albumin & $32(28.1)$ & $32(30.5)$ & $0(0)$ & $0(0)$ & $0(0)$ & $41(21.0)$ & $39(27.7)$ & $2(3.9)^{\mathrm{f}}$ & $0(0)$ & $2(3.7)^{\mathrm{g}}$ \\
\hline Hemoglobin & $68(59.7)$ & $65(61.9)$ & $0(0)$ & $3(33.3)$ & $3(33.3)$ & $78(40.0)^{\mathrm{b}}$ & $66(46.8)^{\mathrm{a}}$ & $11(21.6)^{\mathrm{e}}$ & $1(33.3)$ & $12(22.2)^{\mathrm{e}}$ \\
\hline Iron & $43(37.7)$ & $41(39.1)$ & $0(0)$ & $2(22.2)$ & $2(22.2)$ & $48(24.6)^{\mathrm{a}}$ & $41(29.1)$ & $7(13.7)^{\mathrm{e}}$ & $0(0)$ & $7(13.0)^{\mathrm{e}}$ \\
\hline B12 & $6(5.3)$ & $6(5.7)$ & $0(0)$ & $0(0)$ & $0(0)$ & $32(16.4)^{\mathrm{a}}$ & $29(20.57)^{\mathrm{b}}$ & $3(5.9)^{\mathrm{e}}$ & $0(0)$ & $3(5.6)^{\mathrm{e}}$ \\
\hline Folate & $5(4.4)$ & $5(4.8)$ & $0(0)$ & $0(0)$ & $0(0)$ & $5(2.6)$ & $5(3.6)$ & $0(0)$ & $0(0)$ & $0(0)$ \\
\hline \multirow[t]{4}{*}{ CRP } & $59(51.8)$ & $58(55.2)$ & $0(0)$ & $1(11.1)^{\mathrm{e}}$ & $1(11.1)^{\mathrm{e}}$ & $74(38.0)^{\mathrm{a}}$ & $66(46.8)$ & $6(11.8)^{\mathrm{g}}$ & $2(66.7)$ & $8(14.8)^{\mathrm{f}}$ \\
\hline & \multicolumn{5}{|c|}{ Female Children, No. (\%) } & \multicolumn{5}{|c|}{ Female Adults, No. $(\%)$} \\
\hline & Total & $\mathrm{CD}$ & $\mathrm{UC}$ & IBDU & $\mathrm{UC}+\mathrm{IBDU}$ & Total & $\mathrm{CD}$ & $\mathrm{UC}$ & IBDU & $\mathrm{UC}+\mathrm{IBDU}$ \\
\hline & $(\mathrm{n}=89)$ & $(\mathrm{n}=74)$ & $(\mathrm{n}=4)$ & $(\mathrm{n}=11)$ & $(\mathrm{n}=15)$ & $(\mathrm{n}=192)$ & $(\mathrm{n}=133)$ & $(n=46)$ & $(n=13)$ & $(\mathrm{n}=59)$ \\
\hline Albumin & $25(28.1)$ & $23(31.1)$ & $0(0)$ & $2(18.2)$ & $2(13.3)$ & $50(26.0)$ & $41(30.8)$ & $8(17.4)^{\mathrm{d}}$ & $1(7.7)$ & $9(15.3)^{\mathrm{e}}$ \\
\hline Hemoglobin & $52(58.4)$ & $44(59.5)$ & $3(75.0)$ & $5(45.5)$ & $8(53.3)$ & $65(33.9)^{c}$ & $56(42.1)^{\mathrm{a}}$ & $7(15.2)^{\mathrm{e}}$ & $2(15.4)$ & $9(15.3)^{\mathrm{a}, \mathrm{f}}$ \\
\hline Iron & $34(38.2)$ & $31(41.9)$ & $0(0)$ & $3(27.3)$ & $3(20.0)$ & $50(26.0)^{\mathrm{a}}$ & $44(33.1)$ & $6(13.0)^{\mathrm{e}}$ & $0(0)$ & $6(10.2)^{\mathrm{f}}$ \\
\hline B12 & $5(5.6)$ & $4(5.4)$ & $0(0)$ & $1(9.1)$ & $1(6.7)$ & $43(22.4)^{\mathrm{b}}$ & $43(32.3)^{\mathrm{c}, \mathrm{d}}$ & $0(0)^{\mathrm{g}}$ & $0(0)^{\mathrm{e}}$ & $0(0)^{\mathrm{g}}$ \\
\hline Folate & $1(1.1)$ & $1(1.4)$ & $0(0)$ & $0(0)$ & $0(0)$ & $5(2.6)$ & $4(3.01)$ & $1(2.2)$ & $0(0)$ & $1(1.7)$ \\
\hline CRP & $42(47.2)$ & $41(55.4)$ & $0(0)$ & $1(9.1)^{\mathrm{e}}$ & $1(6.7)^{\mathrm{f}}$ & 75 (39.1) & $64(48.1)$ & $9(19.6)^{\mathrm{e}}$ & $2(15.4)$ & $11(18.6)^{\mathrm{f}}$ \\
\hline
\end{tabular}

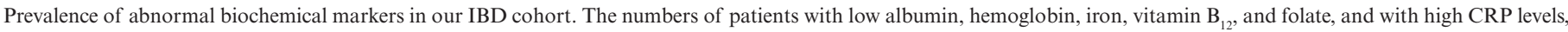
are shown.

${ }^{\mathrm{a}} P<0.05,{ }^{\mathrm{b}} P<0.001,{ }^{\mathrm{c}} P<0.0001$ vs children.

${ }^{\mathrm{d}} P<0.05$ vs male.

${ }^{\mathrm{e}} P<0.05,{ }^{\mathrm{f}} P<0.0002,{ }^{\mathrm{g}} P<0.0001$ vs $\mathrm{CD}$.

This significant difference was also observed for the $\mathrm{CD}, \mathrm{UC}$, and UC+IBDU subgroups and in both the male and female cohorts. In adults, the prevalence of anemia was higher in subjects with CD compared with those with UC or UC+IBDU (44.5\%, 18.6\%, and $18.5 \%$, respectively, $P<0.0001)$. This was also significant in the adult male and female cohorts but was not observed in the pediatric population. Also, we found that a large proportion of undernourished patients had anemia $(92 \%$ of children and $80 \%$ of adults). However, a considerable proportion of patients who had normal BMI also presented with anemia ( $41 \%$ of children and $61 \%$ of adults).

The frequency of low blood $\mathrm{Fe}$ was higher in children compared with adults for the total IBD groups $(37.9 \%$ vs $25.3 \%, P<0.0017)$. This remained significant when the male and female groups were analyzed independently. In adults only, low $\mathrm{Fe}$ was more frequent in the $\mathrm{CD}$ group compared with the UC and UC+IBDU groups $(31.0 \%, 13.4 \%$, and $11.5 \%$, respectively, $P<0.0007$ ).

We further analyzed the prevalence of anemia based on age at diagnosis (pediatric vs adult) rather than chronological age at the time of testing. Adults with onset of IBD in the pediatric age group were more often anemic than those diagnosed after age 17 (45.3\% vs $30.9 \%, P<0.005$; data not shown). The same outcome was found with the evaluation of low blood $\mathrm{Fe}$ levels according to age at diagnosis $(31.1 \%$ vs $21.2 \%, P<0.033$; data not shown). When analyzed according to sex, the difference in frequencies for low albumin and $\mathrm{Fe}$ according to age at diagnosis remained significant for women only. 
Next, we assessed anemia status in relationship with iron supplementation. In $\mathrm{CD}$, the proportion of anemic children taking Fe supplements was $60.6 \%$ (53.8\% in boys and $70.5 \%$ in girls), which was not significantly different from adults (proportion of $45.9 \%, 42.4 \%$ in men and $50.0 \%$ in women). Also, most of the subjects taking Fe supplements were diagnosed with low $\mathrm{Hb}$ levels at least at 1 visit during their follow-up $(85.4 \%$ of boys, $79.5 \%$ of girls, $75.7 \%$ of men, and $90.3 \%$ of women).

Vitamin $\mathrm{B}_{12}$ deficiency was less common in the pediatric than the adult groups for $\mathrm{CD}(5.6 \%$ vs $26.3 \%, P<0.0001)$, but not in the UC or IBDU groups. In adults, the proportion of subjects with low $\mathrm{B}_{12}$ was higher in $\mathrm{CD}$ compared with UC and IBDU $(P<0.0001)$. Adult men had a lower prevalence of $\mathrm{B}_{12}$ deficiency than women ( $20.6 \%$ vs $32.3 \%, P<0.05$ ). In children with $\mathrm{CD}, 36.4 \%$ of subjects with low $\mathrm{B}_{12}$ levels were receiving $B_{12}$ supplementation (33.3\% in boys and $40.0 \%$ in girls), whereas in adults with $\mathrm{CD}, 52.7 \%$ of subjects with low $\mathrm{B}_{12}$ were taking $\mathrm{B}_{12}$ supplements (52.0\% men and $53.4 \%$ women). These proportions were not significantly different. Among the $3 \mathrm{UC}$ male adult patients who had $\mathrm{B}_{12}$ deficiency, 1 was taking $\mathrm{B}_{12}$ supplements. Relatively few subjects had low folate levels (3.0\% in children and $2.7 \%$ in adults).

We evaluated the prevalence of high CRP levels as a biomarker of inflammation. Pediatric IBD patients more often had an elevated CRP ( $49.8 \%$ vs $38.4 \%, P<0.01)$. The proportion of patients with an elevated CRP was greater in CD compared with $\mathrm{UC}$ and $\mathrm{UC}+\mathrm{IBDU}$ in children $(P<0.001)$ and in adults $(P<0.0001)$. No differences were observed based on sex.

\section{Prevalence of Active Disease}

We assessed the proportion of children and adults presenting at a visit with active disease. Among all IBD types, this proportion was not different between children and adults. However, when data were analyzed for $\mathrm{CD}$, there were more adults than children with active disease $(41.2 \%$ vs $31.8 \%$, $P<0.05$ ). In both groups, males were less likely than females to present with active disease, but the difference was only significant in adults $(30.8 \%$ vs $44.3 \%, P<0.0065)$. This finding between men and women was also found in CD only (31.9\% vs $51.1 \%, P<0.0014)$.

To assess the correlation between disease activity and undernutrition, we calculated, for each group, the percentage of both the presence of undernutrition and high disease activity score at each visit. Among male children with $\mathrm{CD}$, when severe undernutrition was recorded at a visit, there was a high HBI score $25.0 \%$ of the time. In this group, the number was $20 \%$ for mild undernutrition. These proportions were more elevated in female children, as a high disease activity score was recorded $100 \%$ of the time in cases with severe undernutrition, but only $30.0 \%$ of the time in cases with mild undernutrition. In male adults with $\mathrm{CD}$, an $\mathrm{HBI}>4$ and undernutrition were observed simultaneously at $61.5 \%$ of visits for severe and $11.0 \%$ for mild undernutrition. In women with $\mathrm{CD}$, these percentages were $66.7 \%$ for severe and $44.4 \%$ for mild undernutrition. In male adults with UC, there was severe undernutrition and an LI score $>266.7 \%$ of the time. As for female adults with UC, the proportions were $60.0 \%$ for severe and $50.0 \%$ for mild undernutrition. The 2 women with IBDU and severe undernutrition did not have a high LI score at visits. None of these differences were statistically significant.

We have also analyzed the relationship between serum albumin and CRP with disease activity in CD. Seventy-seven percent of children and $67 \%$ of adults with active disease had high CRP, compared with $48 \%$ and $43 \%$ with low albumin, showing that CRP is a better surrogate of disease activity than serum albumin. However, CRP was found to be very unspecific as $45 \%$ of children and $38 \%$ of adults without active disease presented with high CRP, compared with 23\% (children) and 21\% (adults) for low albumin. Differences between children and adults were not statistically significant.

\section{Disease Location and Behavior and Undernutrition in CD}

We next assessed the association between variables relative to nutritional status and undernutrition. Because of the low number of patients with undernutrition in the UC and IBDU groups, analyses were only conducted in CD patients. Data for disease location were available for 188 children and 366 adults, whereas data for disease behavior were available for 200 pediatric and 376 adult patients. Most children had ileocolonic (83.5\%) and luminal disease $(84.5 \%)$. A majority of adults also presented with ileocolonic disease $(54.9 \%)$, but unique colonic involvement was more prevalent $(25.7 \%)$ than in children. To assess if certain variables were associated with undernutrition, we first compared prevalence using $\chi^{2}$ tests (Table 5). These independent analyses revealed that hypoalbuminemia $(P<0.0001)$, low $\mathrm{Hb}$ $(P<0.0001)$, low-serum Fe $(P<0.027)$, high CRP $(P<0.037)$, and ileocolonic disease location $(P<0.004)$ were associated with undernutrition. When all variables were included in a logistic regression model, the associations with hypoalbuminemia (OR, $2.530 ; P<0.006)$ and high disease activity $(\mathrm{OR}, 1.988 ; P<0.03)$ remained significant, whereas the association with ileocolonic disease failed to reach significance (OR, 1.514; $P<0.06)$. When separate models were fit for pediatric and adult patients, similar associations with undernutrition were observed.

\section{Antioxidant Vitamins}

We examined the correlation between the plasma levels of antioxidant vitamins and BMI. Results show a weak but significant correlation $\left(r^{2}=0.103 ; P<0.026\right)$ with plasma levels of retinol. When analyzed by sex, the correlation between retinol and BMI was stronger in females $\left(r^{2}=0.213 ; P<0.027\right)$ but was not existent in males $\left(r^{2}=0.071\right)$. No significant correlation was found with other vitamins. Also, no correlation was observed between antioxidant vitamin levels and HBI score. Next, we 
TABLE 5. Factors Associated With Undernutrition in Pediatric and Adult CD

\begin{tabular}{lcccc}
\hline & \multicolumn{2}{c}{ Chi-Square } \\
\cline { 2 - 3 } & Odds Ratio & Logistic Regression & $P$ \\
\hline Age & 0.920 & $95 \%$ CI & 0.792 & 0.975 \\
Sex & 0.946 & $0.493-1.714$ & 0.852 & 0.006 \\
Low albumin & 2.530 & $0.530-1.689$ & 0.128 & 0.366 \\
Low hemoglobin & 1.730 & $1.304-4.909$ & 0.820 & 0.0001 \\
Low iron & 1.078 & $0.853-3.506$ & 0.005 \\
Low B12 & 0.819 & $0.562-2.067$ & 0.813 & 0.512 \\
Low folate & 1.184 & $0.384-1.746$ & 0.222 & 0.629 \\
High CRP & 0.637 & $0.291-4.821$ & 0.030 \\
High disease activity & 1.988 & $0.309-1.313$ & 0.037 & 0.002 \\
Disease location (ileocolonic) & 1.514 & $1.068-3.701$ & $0.983-2.333$ & 0.004 \\
Disease behavior & 0.989 & $0.655-1.493$ & 0.260 \\
\hline
\end{tabular}

Predicators of undernutrition in pediatric and adult CD patients, as assessed by logistic regression and by individual $\chi^{2}$ tests.

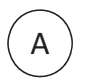

$$
\text { C }
$$

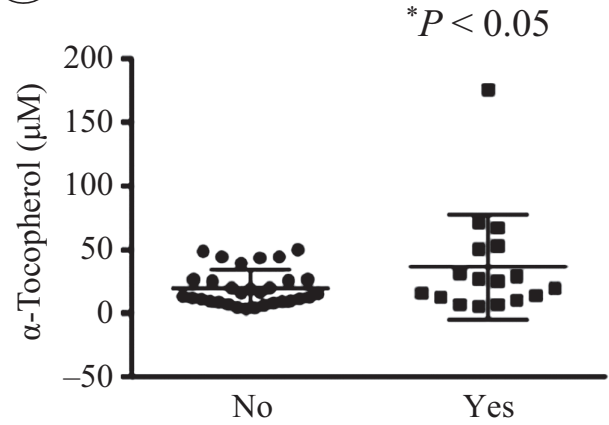

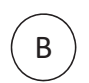

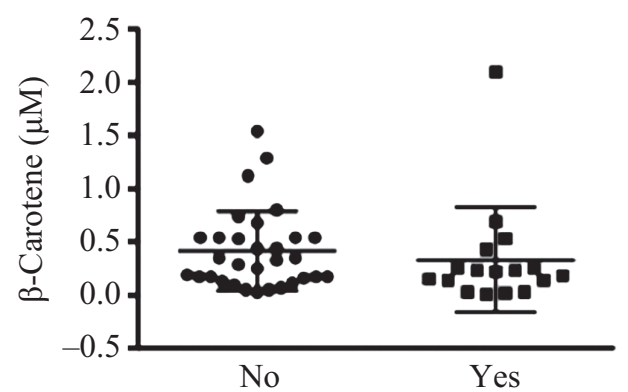

(D)

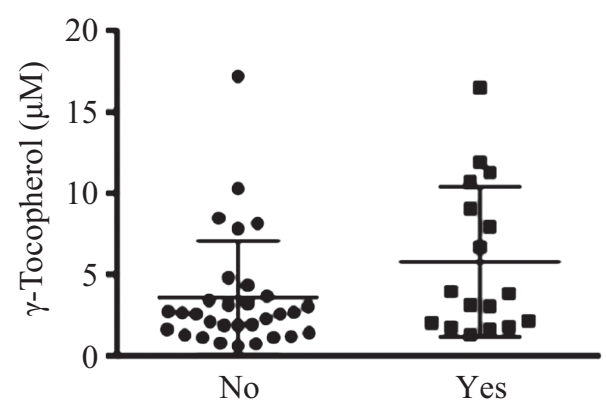

FIGURE 1. Antioxidant vitamin levels according to Fe deficiency. The levels of plasma antioxidant vitamins were analyzed according to Fe deficiency (no/yes). Plasma levels of (A) retinol, (B) $\beta$-carotene, (C) $a$-tocopherol, and (D) $\gamma$-tocopherol were determined in 48 CD adult patients according to their Fe deficiency status. ${ }^{*} P<0.05$ vs no Fe deficiency.

analyzed antioxidant vitamin levels according to undernutrition status (no/yes), active disease (no/yes), high CRP (no/yes), and low levels of albumin, $\mathrm{Hb}, \mathrm{Fe}$, vitamin $\mathrm{B}_{12}$, and folates (no/yes). Levels of antioxidant vitamins were not different in patients with low albumin, $\mathrm{Hb}$, vitamin $\mathrm{B}_{12}$, or folates. However, as shown in
Figure 1, compared with subjects with normal blood $\mathrm{Fe}$ values, patients suffering from Fe deficiency had higher levels of $\alpha$ tocopherol $(19.8 \pm 14.2 \mu \mathrm{M}$ and $36.5 \pm 41.4 \mu \mathrm{M}$, respectively, $P<0.05)$, nonsignificant elevations of retinol $(4.3 \pm 3.2 \mu \mathrm{M}$ and $6.5 \pm 6.1 \mu \mathrm{M}$, respectively, $P<0.10)$ and $\gamma$-tocopherol 
(3.6 $\pm 3.5 \mu \mathrm{M}$ and $5.8 \pm 4.6 \mu \mathrm{M}$, respectively, $P<0.07)$, and a tendency toward reduction in $\beta$-carotene levels $(0.42 \pm 0.37 \mu \mathrm{M}$ and $0.33 \pm 0.49 \mu \mathrm{M}$, respectively, $P<0.06$ ).

Compared with subjects who did not consume supplements, patients who reported taking vitamins displayed higher levels of $\beta$-carotene $(0.31 \pm 0.34 \mu \mathrm{M}$ and $0.59 \pm 0.53 \mu \mathrm{M}$, respectively, $P<0.05)$ and $\alpha$-tocopherol $(20.8 \pm 17.2 \mu \mathrm{M}$ and $38.9 \pm 44.2 \mu \mathrm{M}$, respectively, $P<0.05)$, whereas no significant differences were observed for retinol $(5.0 \pm 4.9 \mu \mathrm{M}$ and $5.3 \pm 3.4 \mu \mathrm{M}$, respectively) or $\gamma$-tocopherol $(4.3 \pm 4.3 \mu \mathrm{M}$ and $4.5 \pm 3.4 \mu \mathrm{M}$, respectively).

\section{Essential Fatty Acid Deficiency}

Reduced ratios of $16: 1 \omega-7 / 18: 1 \omega-6$ and 20: $\omega-9 / 20: 4 \omega-6$ are indicators of EFA deficiency. We analyzed them according to undernutrition status, active disease, high CRP, and low levels of albumin, $\mathrm{Hb}, \mathrm{Fe}$, vitamin $\mathrm{B}_{12}$, and folates. No sig-

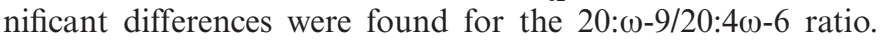
However, subjects with active disease had a lower 16:1 $\omega$ 7/18:1 $\omega-6$ ratio compared with those with inactive disease $(0.23 \pm 0.06$ and $0.18 \pm 0.6$, respectively, $P<0.002)$ (Fig.
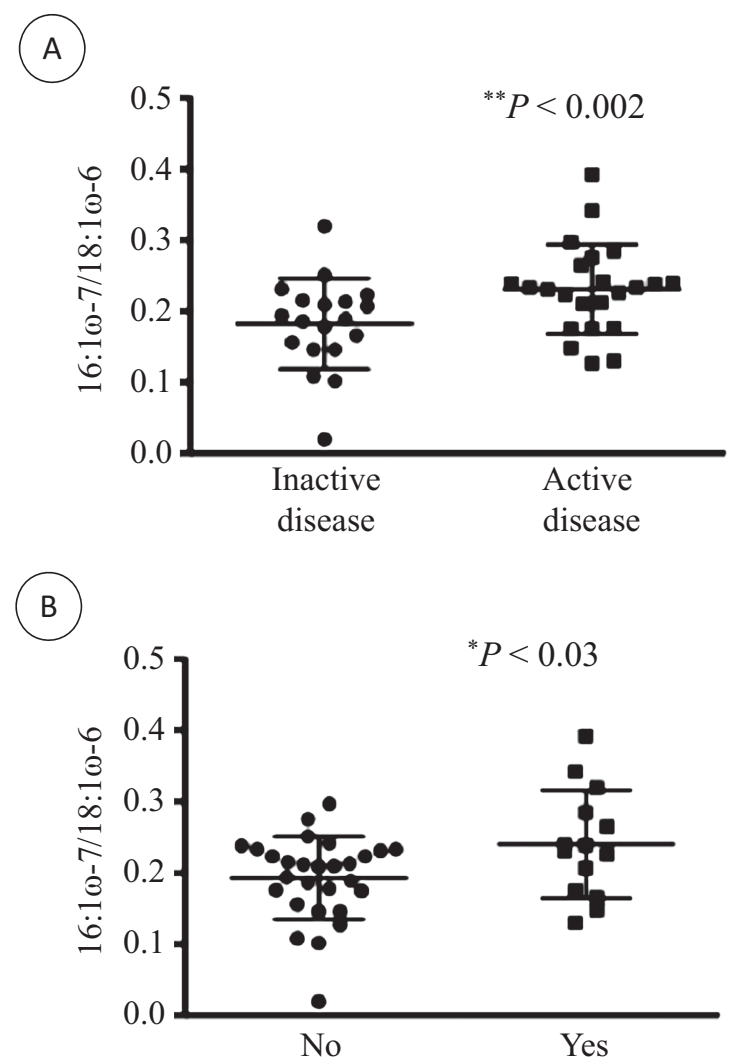

FIGURE 2. Essential fatty acid deficiency according to disease activity and Fe deficiency. Plasma fatty acid levels were determined in $48 \mathrm{CD}$ adult patients, and the ratio between 16:1 $\omega-7$ and $18: 1 \omega-6$ was computed in (A) patients with inactive and active disease and (B) patients without and with Fe deficiency. ${ }^{*} P<0.03$ and ${ }^{* *} P<0.002$ vs inactive disease.
2A). Patients with Fe deficiencies also had a reduced 16:10$7 / 18: 1 \omega-6$ ratio $(0.24 \pm 0.08$ and $0.19 \pm 0.06$, respectively, $P<0.03$ ) (Fig. 2B). When the analyses were performed for sex, these findings remained significant for women $(0.30 \pm 0.06$ and $0.20 \pm 0.07$, respectively, $P<0.01)$ but not for men $(0.20 \pm 0.05$ and $0.18 \pm 0.05$, respectively).

\section{DISCUSSION}

In this cross-sectional study, we aimed to compare the prevalence of malnutrition in children and adults with IBD. When evaluated with BMI or albumin levels, malnutrition was not more common in children compared with adults. However, the measurement of several biochemical parameters reflecting nutritional status revealed that the prevalence of low $\mathrm{Hb}$, low $\mathrm{Fe}$, and high CRP was higher in children, whereas vitamin $\mathrm{B}_{12}$ deficiency was more frequent in adults.

In our cohort, composed of outpatients mainly visiting for routine follow-up appointments, undernutrition was observed in $14.3 \%$ of pediatric patients and $13.7 \%$ of adults, including both severe and mild cases. Some studies reported striking differences in the nutritional status between IBD patients and controls, ${ }^{42,}{ }^{43}$ whereas others did not. ${ }^{16}$ 44, 45 The reported prevalence of undernutrition varies according to the method used for its evaluation and the type of patients examined. Studies that focused on hospitalized IBD patients with severe disease activity reported a high incidence of undernutrition. ${ }^{46,47}$ A study examining nutritional status in outpatients in remission observed undernutrition in less than 5\% of CD patients according to Subjective Global Assessment (SGA) and BMI, substantially lower than previous studies. ${ }^{48}$ Ladd et al. found that $32.4 \%$ of pediatric CD patients were malnourished, including $4.1 \%$ with severe malnutrition. ${ }^{49}$ In a report including both $\mathrm{CD}$ and UC patients in remission, $\mathrm{CD}$ patients had significantly lower body weights as compared with UC or controls. ${ }^{43}$ Studies found no difference in weight or BMI between CD patients and UC patients or controls. ${ }^{9}, 44,45$ However, Geerling et al. reported lower body fat mass in male patients with $\mathrm{CD}$, and, despite the lack of normally recognized indicators of malnutrition, patients with CD had less power and endurance in their flexor muscles. $^{44,45}$ Using criteria based on BMI, we did not observe a difference in the frequency of undernutrition between $\mathrm{CD}$ and colitis (UC and IBDU), or between males or females. Other measures of nutritional status, such as skin fold thickness, could have led to different results. Malnutrition, defined with BMI, was found in $14.0 \%$ of subjects with CD and $5.7 \%$ of UC patients, whereas muscle mass depletion, measured by triceps plus subscapular skin fold thickness and by arm muscle area, was detected in more than half of the CD and UC patients. ${ }^{50}$ Nonetheless, as BMI is a simple and useful tool in clinical practice and comparisons between anthropometric parameters have already been performed in IBD, it was selected as our indicator for undernutrition. 
It has been demonstrated that treatment choice can impact nutritional status in IBD patients. For example, infliximab, ${ }^{30}$ steroids, ${ }^{51}$ and enteral nutrition therapy ${ }^{51}$ can improve BMI. However, our results show that there was no difference in the proportion of undernourished and well-nourished adults treated with steroids and/or a biological. On the contrary, we observed that steroids and biologicals were more frequently used in undernourished children compared with those who were well-nourished. This difference might reflect more severe disease in children taking these medications.

It was reported that a high proportion of hospitalized CD $(25 \%-80 \%)$ and UC patients $(25 \%-50 \%)$ have hypoalbuminemia. ${ }^{52}$ We found that $28.1 \%$ of children and $23.5 \%$ of adults, mostly outpatients, had hypoalbuminemia. The prevalence of hypoalbuminemia was higher in CD compared with UC and IBDU patients, in both pediatric and adult cohorts. Circulating albumin levels, along with BMI, are often used as a nutritional assessment in IBD patients, ${ }^{53}$ although low albumin levels better reflect the status of inflammation. ${ }^{54}$ In our study, even when including cases with mild undernutrition (using $\mathrm{BMI}$ ), the prevalence was almost half that of low-serum albumin. In line with our results, it has been pointed out that BMI underestimates malnutrition and should be used with caution, especially in IBD patients. ${ }^{55}$ Some patients classified as overweight or obese with BMI were found to be malnourished based on triceps skin folds and handgrip strength. ${ }^{55}$ In that study, the prevalence of malnutrition based on BMI was only $6.0 \%$, but was found to be as high as $73.3 \%$ when assessed with handgrip strength. ${ }^{55}$ As BMI is such a simple clinical tool to use, we believe that determining its correlation with other markers of nutritional status is useful for proper assessment, in keeping with a recent position paper on nutritional status in pediatric IBD. ${ }^{56}$

The specific considerations of pediatric-onset IBD in terms of their nutritional needs are well recognized. ${ }^{56,57}$ Growth during childhood and adolescence increases nutritional requirements, which can be difficult to meet in a patient with IBD. Growth failure is seen in about $30 \%$ of children with CD from 9 years of age to adolescence and in $5 \%-10 \%$ of children with UC. ${ }^{58}$ Permanent short stature in patients with pediatriconset $\mathrm{CD}$ has been reported in $19 \%-35 \%$ of patients, ${ }^{24,} 59$ whereas it is relatively rare in pediatric-onset UC. ${ }^{59}$ Given the additional nutritional challenge of growth in children, we were surprised by the similar prevalence of malnutrition found in pediatric and adult groups. These results uphold the need for adequate nutritional assessment and follow-up in IBD at any age.

Anemia is a frequent complication of IBD, with reported prevalence varying between $19 \%$ and $60 \%{ }^{60,61}$ Anemia has significant impact on quality of life, contributing to chronic fatigue. Both $\mathrm{Fe}$ deficiency and anemia of chronic disease contribute most to the development of anemia in IBD. ${ }^{62}$ Our study revealed that, although both children and adults had a high prevalence of low $\mathrm{Hb}$, especially when undernourished, children were at higher risk of anemia. In adults, CD patients were at higher risk of low $\mathrm{Hb}$ compared with those with UC or IBDU. Low Fe levels were also more prevalent in children than adults, and in CD compared with UC or IBDU. Fe deficiency is the most common micronutrient deficiency in IBD and may be a result of malabsorption, impaired dietary intake, inflammation, or chronic intestinal blood loss. ${ }^{61} \mathrm{Fe}$ deficiency anemia in adults with IBD was found in 6\%-73\%, depending on disease type and diagnostic criteria. ${ }^{63,64}$ In a study in pediatric IBD, the reported prevalence was $17 \% .{ }^{65}$ This discrepancy in frequency may be partially caused by differences in diagnostic criteria and the populations studied. A higher prevalence of anemia is seen in hospitalized patients. As most studies were performed at referral centers, one can speculate that they may have overestimated the actual prevalence in a community-based setting. However, despite being focused on a population largely comprised of outpatients, our study underlines the high prevalence of anemia and low Fe in IBD, especially in children and particularly in CD.

It has been reported that, in spite of appropriate energy and macronutrient intakes, CD patients in remission have lower plasma concentrations of several vitamins and minerals. ${ }^{61,66,67}$ In particular, vitamin $\mathrm{B}_{12}$ and folate deficiencies are common in IBD. We found that the prevalence of vitamin $\mathrm{B}_{12}$ deficiency was significantly higher in adults $(19.4 \%)$ compared with children $(5.4 \%)$. Women with CD were particularly at risk for vitamin $\mathrm{B}_{12}$ deficiency, with a prevalence of $32.3 \%$. Because absorption of vitamin $\mathrm{B}_{12}$ requires an intact and functional ileum, it has been assumed that patients with $\mathrm{CD}$ are at high risk for $\mathrm{B}_{12}$ deficiency. ${ }^{68}$ We found that vitamin $\mathrm{B}_{12}$ deficiency was greater in adults with $\mathrm{CD}$ than in those with UC or IBDU (26.3\% vs $2.6 \%$ ). Similarly, two studies found a higher prevalence of low serum $\mathrm{B}_{12}$ in CD compared to UC: $18.4 \%$ vs $5 \%{ }^{68}$ and $22 \%$ vs $7.5 \% .{ }^{53}$ Oostenbrug and collaborators found that $41.9 \%$ of patients with ileal CD had low-serum cobalamin levels, compared with $20.7 \%$ in patients with disease confined to the colon. ${ }^{69}$ We recently reported that ileal resection exceeding $20 \mathrm{~cm}$ is a risk factor for $\mathrm{B}_{12}$ deficiency. ${ }^{20}$

The prevalence of folate deficiency was relatively low in our study $(3.0 \%$ in children, $2.6 \%$ in adults). This can be explained by the widespread consumption of folate supplements among IBD patients. In line with our findings, folate concentrations have been reported to be normal or low compared with those in non-IBD controls in adult ${ }^{61,70}$ and pediatric $^{71}$ IBD patients. Studies have even observed higher serum, leukocyte, and red blood cell folate concentrations in pediatric patients with newly diagnosed IBD than in controls. ${ }^{72}$ However, other studies have reported higher folate deficiencies in adults with IBD, $10 \%-29 \%$ in CD patients and $8.6 \%$ in UC patients. ${ }^{53,70}$ A meta-analysis found that folate concentrations in patients with UC but not CD were lower than those in controls. ${ }^{73}$

CRP is produced mainly in hepatocytes in response to acute phase stimuli such as inflammatory cytokines and is commonly used to monitor disease activity in IBD. ${ }^{37} \mathrm{CRP}$ levels are 
known to correlate with clinical disease activity, endoscopic inflammation, and active histological inflammation. ${ }^{74}$ In our study, the prevalence of high CRP levels was elevated in both age groups, although it was more frequent in children than in adults $(49.8 \%$ vs $38.5 \%)$ and in adult CD compared with UC and IBDU (47.4\% vs $16.8 \%)$. Others have also observed that CD patients have higher CRP levels than those with UC. ${ }^{75}$ One study showed that $75 \%$ of $\mathrm{CD}$ and $29 \%$ of UC adult patients had elevated CRP levels at diagnosis, ${ }^{38}$ which is higher than our findings. In a pediatric study, CRP was detectable in $36 \%$ of patients, but serum levels were independent of disease activity. ${ }^{37}$

Searching for variables that can predict undernutrition revealed that hypoalbuminemia and high disease activity had the strongest associations, for both the pediatric and adult groups. Low $\mathrm{Hb}$, low $\mathrm{Fe}$, high $\mathrm{CRP}$, and ileocolonic disease location were also associated with undernutrition. Similarly, it was found that BMI and serum albumin were the best predicators of nutritional status in IBD patients with active disease. ${ }^{53} \mathrm{In}$ children, tructuring disease turned out to be the disease behavior most often associated with impaired nutritional status. ${ }^{76}$ In hospitalized $\mathrm{CD}$ patients, malnutrition on admission was more frequent in those with active fistulizing disease than in those without this complication. ${ }^{1}$ Our data did not reveal any predicative value of disease behavior.

Our results showed that retinol levels correlated with BMI but only in women. A meta-analysis of 19 case-control studies revealed that levels of fat-soluble vitamins, including vitamin A, were lower in patients with IBD. ${ }^{77}$ In the EUREYE study, which included 4753 participants, BMI was one of the factors positively associated with plasma retinol levels. ${ }^{78}$ The reasons why this was only significant in women in our study are not clear, but might be explained by the small sample size. Interestingly, levels of retinol, $\alpha$-tocopherol, and $\gamma$-tocopherol were elevated in patients with low blood $\mathrm{Fe}$. As $\mathrm{Fe}$ is known to promote oxidative stress, ${ }^{79}$ it is rational to presume that, as less antioxidant protection is needed in these patients, levels of antioxidant vitamins are higher.

Aberrations in plasma fatty acid profiles of CD patients have been reported previously, ${ }^{39}$ and altered EFA profiles have been correlated with disease activity in children. ${ }^{80}$ Our data found EFA deficiency in adult CD patients with active disease and revealed its relation to blood Fe status, implicating elevated oxidative stress.

To enhance the feasibility of the McGill IBD Database, only values outside normal cutoffs were registered. Consequently, the lack of normal values for biological parameters is a limitation of this study. Moreover, we did not systematically collect data on caloric and nutrient intake, preventing us exploring the specific factors causing malnutrition, such as decreased intake, increased loss, or malabsorption.

Furthermore, disease activity was calculated using HBI (CD) and LI (UC and IBDU) for both pediatric and adult populations. These indexes, which do not require endoscopy score or laboratory results, were used for practicality and efficiency. The Pediatric Crohn's
Disease Activity Index (PCDAI) and Pediatric Ulcerative Colitis Activity Index (PUCAI) have become the standard indices for measuring disease activity in pediatric $\mathrm{CD}$ and $\mathrm{UC}$, respectively, but the PCDAI necessitates endoscopy and laboratory testing. However, the HBI and LI have been validated and employed in several pediatric studies. As we only needed to discriminate between active and inactive disease, without gradation based on severity, we believe that the HBI and LI adequately captured active disease in our pediatric population.

Another limitation is that vitamin $\mathrm{B}_{12}$ deficiency may have been poorly diagnosed or misdiagnosed in the IBD population, as blood levels were found insufficient to identify deficiency in asymptomatic patients..$^{18}$ Also, we did not collect data on total iron-binding capacity, ferritin, or transferrin, which could have been used to assess iron deficiency anemia.

In conclusion, data from our McGill University Health Center IBD database show that malnutrition, as measured by undernutrition using BMI and hypoalbuminemia, is seen in adult IBD patients as often as in children. Additionally, high disease activity and low albumin levels are strong predicators of malnutrition in $\mathrm{CD}$, both in pediatric and adult patients. Anemia, low-serum Fe, and high CRP are more frequently observed in pediatric $\mathrm{CD}$ patients, compared with adults. Vitamin $\mathrm{B}_{12}$ deficiency is more common in adult compared with pediatric $\mathrm{CD}$ patients. Participants with active disease and $\mathrm{Fe}$ deficiency had a lower 16:1 $\omega-7 / 18: 1 \omega-6$ ratio, an indicator of EFA deficiency. These results justify close follow-up of nutritional status for IBD patients regardless of age.

\section{SUPPLEMENTARY DATA}

Supplementary data are available at Inflammatory Bowel Diseases online.

\section{ACKNOWLEDGMENTS}

The authors thank Mrs. Melissa Diamond for her technical assistance.

\section{REFERENCES}

1. Nguyen GC, Munsell M, Harris ML. Nationwide prevalence and prognostic significance of clinically diagnosable protein-calorie malnutrition in hospitalized in flammatory bowel disease patients. Inflamm Bowel Dis. 2008;14:1105-1111.

2. Gassull MA, Cabré E. Nutrition in inflammatory bowel disease. Curr Opin Clin Nutr Metab Care. 2001;4:561-569.

3. Lanfranchi GA, Brignola C, Campieri M, et al. Assessment of nutritional status in Crohn's disease in remission or low activity. Hepatogastroenterology. 1984;31:129-132.

4. Valentini L, Schaper L, Buning C, et al. Malnutrition and impaired muscle strength in patients with Crohn's disease and ulcerative colitis in remission. Nutrition. 2008;24:694-702.

5. Bergeron F, Bouin M, D'Aoust L, et al. Food avoidance in patients with inflammatory bowel disease: what, when and who? Clin Nutr. 2018;37:884-889.

6. Hermann GE, Rogers RC. TNF activates astrocytes and catecholaminergic neurons in the solitary nucleus: implications for autonomic control. Brain Res. 2009;1273:72-82.

7. Al-Jaouni R, Hébuterne X, Pouget I, et al. Energy metabolism and substrate oxidation in patients with Crohn's disease. Nutrition. 2000;16:173-178.

8. Vaisman N, Dotan I, Halack A, et al. Malabsorption is a major contributor to underweight in Crohn's disease patients in remission. Nutrition. 2006;22:855-859.

9. Diederen K, Krom H, Koole JCD, et al. Diet and anthropometrics of children with inflammatory bowel disease: acomparison with the general population. Inflamm Bowel Dis. 2018;24:1632-1640. 
10. Lim HS, Kim SK, Hong SJ. Food elimination diet and nutritional deficiency in patients with inflammatory bowel disease. Clin Nutr Res. 2018;7:48-55.

11. Ling SC, Griffiths AM. Nutrition in inflammatory bowel disease. Curr Opin Clin Nutr Metab Care. 2000;3:339-344

12. Kulnigg S, Stoinov S, Simanenkov V, et al. A novel intravenous iron formulation for treatment of anemia in inflammatory bowel disease: the ferric carboxymaltose (FERINJECT) randomized controlled trial. Am J Gastroenterol. 2008;103:1182-1192

13. Semrin G, Fishman DS, Bousvaros A, et al. Impaired intestinal iron absorption in Crohn's disease correlates with disease activity and markers of inflammation. Inflamm Bowel Dis. 2006;12:1101-1106.

14. Gasché C, Reinisch W, Lochs H, et al. Anemia in Crohn's disease. Importance of inadequate erythropoietin production and iron deficiency. Dig Dis Sci. 1994;39:1930-1934.

15. Gomollón F, Gisbert JP. Anemia and inflammatory bowel diseases. World $J$ Gastroenterol. 2009;15:4659-4665.

16. Felipez LM, Gokhale R, Tierney MP, et al. Thalidomide use and outcomes in pediatric patients with Crohn disease refractory to infliximab and adalimumab. $J$ Pediatr Gastroenterol Nutr. 2012;54:28-33.

17. Reimund JM, Hirth C, Koehl C, et al. Antioxidant and immune status in active Crohn's disease. A possible relationship. Clin Nutr. 2000;19:43-48.

18. Battat R, Kopylov U, Szilagyi A, et al. Vitamin B12 deficiency in inflammatory bowel disease: prevalence, risk factors, evaluation, and management. Inflamm Bowel Dis. 2014;20:1120-1128.

19. Morgenstern I, Raijmakers MT, Peters WH, et al. Homocysteine, cysteine, and glutathione in human colonic mucosa: elevated levels of homocysteine in patients with inflammatory bowel disease. Dig Dis Sci. 2003;48:2083-2090.

20. Battat R, Kopylov U, Byer J, et al. Vitamin B12 deficiency in inflammatory bowel disease: a prospective observational pilot study. Eur J Gastroenterol Hepatol. 2017;29:1361-1367.

21. O'Sullivan, MA, O'Morain CA. Nutritional therapy in Crohn's disease. Inflamm Bowel Dis. 1998;4:45-53.

22. Seidman E, LeLeiko N, Ament M, et al. Nutritional issues in pediatric inflammatory bowel disease. J Pediatr Gastroenterol Nutr. 1991;12:424 438.

23. Motil KJ, Grand RJ, Davis-Kraft L, et al. Growth failure in children with inflammatory bowel disease: a prospective study. Gastroenterology. 1993;105:681-691.

24. Sentongo TA, Semeao EJ, Piccoli DA, et al. Growth, body composition, and nutritional status in children and adolescents with Crohn's disease. J Pediatr Gastroenterol Nutr. 2000;31:33-40.

25. Silverberg MS, Satsangi J, Ahmad T, et al. Toward an integrated clinical, molecular and serological classification of inflammatory bowel disease: report of a working party of the 2005 Montreal World Congress of Gastroenterology. Can J Gastroenterol. 2005;19(Suppl A):5A-36A.

26. Harvey RF, Bradshaw JM. A simple index of Crohn's-disease activity. Lancet. 1980;1:514

27. Lichtiger S, Present DH, Kornbluth A, et al. Cyclosporine in severe ulcerative colitis refractory to steroid therapy. $N$ Engl J Med. 1994;330:1841-1845.

28. WHO. Physical status: the use and interpretation of anthropometry. Report of a WHO Expert Committee. World Health Organ Tech Rep Ser. 1995;854:1-452.

29. Lipschitz DA. Screening for nutritional status in the elderly. Prim Care. 1994;21:55-67.

30. Vadan R, Gheorghe LS, Constantinescu A, et al. The prevalence of malnutrition and the evolution of nutritional status in patients with moderate to severe forms of Crohn's disease treated with infliximab. Clin Nutr. 2011;30:86-91.

31. Secker DJ, Jeejeebhoy KN. Subjective global nutritional assessment for children. Am J Clin Nutr. 2007;85:1083-1089.

32. Mack DR, Langton C, Markowitz J, et al; Pediatric Inflammatory Bowel Disease Collaborative Research Group. Laboratory values for children with newly diagnosed inflammatory bowel disease. Pediatrics. 2007;119:1113-1119.

33. Gisbert JP, Bermejo F, Pajares R, et al. Oral and intravenous iron treatment in inflammatory bowel disease: hematological response and quality of life improvement. Inflamm Bowel Dis. 2009;15:1485-1491.

34. Yetley EA, Pfeiffer CM, Phinney KW, et al. Biomarkers of vitamin B-12 status in NHANES: a roundtable summary. Am J Clin Nutr. 2011;94:313S-321S.

35. Hercberg S, Galan P. Nutritional anaemias. Baillieres Clin Haematol. 1992;5:143-168.

36. Yakut M, Ustün Y, Kabaçam G, et al. Serum vitamin B12 and folate status in patients with inflammatory bowel diseases. Eur J Intern Med. 2010;21:320-323.

37. Sidoroff M, Karikoski R, Raivio T, et al. High-sensitivity C-reactive protein in paediatric inflammatory bowel disease. World J Gastroenterol. 2010;16:2901-2906.

38. Henriksen M, Jahnsen J, Lygren I, et al; IBSEN Study Group. C-reactive protein: a predictive factor and marker of inflammation in inflammatory bowel disease. Results from a prospective population-based study. Gut. 2008;57:1518-1523.

39. Levy E, Rizwan Y, Thibault L, et al. Altered lipid profile, lipoprotein composition, and oxidant and antioxidant status in pediatric Crohn disease. Am J Clin Nutr. 2000;71:807-815.

40. Lepage G, Levy E, Ronco N, et al. Direct transesterification of plasma fatty acids for the diagnosis of essential fatty acid deficiency in cystic fibrosis. $J$ Lipid Res. 1989;30:1483-1490.
41. Spahis S, Vanasse M, Bélanger SA, et al. Lipid profile, fatty acid composition and pro- and anti-oxidant status in pediatric patients with attention-deficit/hyperactivity disorder. Prostaglandins Leukot Essent Fatty Acids. 2008;79:47-53.

42. Jahnsen J, Falch JA, Mowinckel P, et al. Body composition in patients with inflammatory bowel disease: a population-based study. Am J Gastroenterol. 2003; $98: 1556-1562$

43. Capristo E, Addolorato G, Mingrone G, et al. Effect of disease localization on the anthropometric and metabolic features of Crohn's disease. Am J Gastroenterol. 1998:93:2411-2419.

44. Geerling BJ, Badart-Smook A, Stockbrügger RW, et al. Comprehensive nutritional status in recently diagnosed patients with inflammatory bowel disease compared with population controls. Eur J Clin Nutr. 2000;54:514-521.

45. Geerling BJ, Badart-Smook A, Stockbrügger RW, et al. Comprehensive nutritional status in patients with long-standing Crohn disease currently in remission. Am J Clin Nutr. 1998;67:919-926.

46. Fernandez-Banares F, Abad-Lacruz A, Xiol X, et al. Vitamin status in patients with inflammatory bowel disease. Am J Gastroenterol. 1989;84:744-748.

47. Fernández-Bañares F, Mingorance MD, Esteve M, et al. Serum zinc, copper, and selenium levels in inflammatory bowel disease: effect of total enteral nutrition on trace element status. Am J Gastroenterol. 1990;85:1584-1589.

48. Sousa Guerreiro C, Cravo M, Costa AR, et al. A comprehensive approach to evaluate nutritional status in Crohn's patients in the era of biologic therapy: case-control study. Am J Gastroenterol. 2007;102:2551-2556.

49. Ladd MR, Garcia AV, Leeds IL, et al. Malnutrition increases the risk of 30-day complications after surgery in pediatric patients with Crohn disease. J Pediatr Surg. 2018;53:2336-2345.

50. Rocha R, Santana GO, Almeida N, et al. Analysis of fat and muscle mass in patients with inflammatory bowel disease during remission and active phase. $\mathrm{Br} \mathrm{J}$ Nutr. 2009;101:676-679.

51. Nielsen AA, Nielsen JN, Grønbaek H, et al. Impact of enteral supplements enriched with omega-3 fatty acids and/or omega- 6 fatty acids, arginine and ribonucleic acid compounds on leptin levels and nutritional status in active Crohn's disease treated with prednisolone. Digestion. 2007;75:10-16.

52. Goh J, O'Morain CA. Review article: nutrition and adult inflammatory bowe disease. Aliment Pharmacol Ther. 2003;17:307-320.

53. Mijac DD, Janković GL, Jorga J, et al. Nutritional status in patients with active inflammatory bowel disease: prevalence of malnutrition and methods for routine nutritional assessment. Eur J Intern Med. 2010;21:315-319.

54. Seres DS. Surrogate nutrition markers, malnutrition, and adequacy of nutrition support. Nutr Clin Pract. 2005;20:308-313.

55. Bin CM, Flores C, Alvares-da-Silva MR, et al. Comparison between handgrip strength, subjective global assessment, anthropometry, and biochemical marker in assessing nutritional status of patients with Crohn's disease in clinical remission. Dig Dis Sci. 2010;55:137-144

56. Miele E, Shamir R, Aloi M, et al. Nutrition in pediatric inflammatory bowe disease: a position paper on behalf of the Porto Inflammatory Bowel Disease Group of the European Society of Pediatric Gastroenterology, Hepatology and Nutrition. J Pediatr Gastroenterol Nutr. 2018;66:687-708.

57. Kim SC, Ferry GD. Inflammatory bowel diseases in pediatric and adolescent patients: clinical, therapeutic, and psychosocial considerations. Gastroenterology. 2004; 126:1550-1560.

58. Mallon DP, Suskind DL. Nutrition in pediatric inflammatory bowel disease. Nutr Clin Pract. 2010;25:335-339.

59. Markowitz J, Grancher K, Rosa J, et al. Growth failure in pediatric inflammatory bowel disease. J Pediatr Gastroenterol Nutr. 1993;16:373-380.

60. Eriksson C, Henriksson I, Brus O, et al. Incidence, prevalence and clinical outcome of anaemia in inflammatory bowel disease: a population-based cohort study. Aliment Pharmacol Ther. 2018;48:638-645.

61. Vagianos K, Bector S, McConnell J, et al. Nutrition assessment of patients with inflammatory bowel disease. JPEN $J$ Parenter Enteral Nutr. 2007:31:311-319.

62. Gasche C, Lomer MC, Cavill I, et al. Iron, anaemia, and inflammatory bowe diseases. Gut. 2004;53:1190-1197.

63. Ebinger M, Leidl R, Thomas S, et al. Cost of outpatient care in patients with inflammatory bowel disease in a German university hospital. $J$ Gastroenterol Hepatol. 2004;19:192-199.

64. Kulnigg S, Gasche C. Systematic review: managing anaemia in Crohn's disease. Aliment Pharmacol Ther. 2006;24:1507-1523.

65. Revel-Vilk S, Tamary H, Broide E, et al. Serum transferrin receptor in children and adolescents with inflammatory bowel disease. Eur J Pediatr. 2000;159:585-589.

66. Aghdassi E, Wendland BE, Stapleton M, et al. Adequacy of nutritional intake in a Canadian population of patients with Crohn's disease. J Am Diet Assoc. 2007; 107:1575-1580.

67. Schneider SM, Al-Jaouni R, Filippi J, et al. Sarcopenia is prevalent in patients with Crohn's disease in clinical remission. Inflamm Bowel Dis. 2008; 14:1562-1568.

68. Headstrom PD, Rulyak SJ, Lee SD. Prevalence of and risk factors for vitamin $\mathrm{B}(12)$ deficiency in patients with Crohn's disease. Inflamm Bowel Dis. 2008; 14:217-223 
69. Oostenbrug LE, van Dullemen HM, te Meerman GJ, et al. Clinical outcome of Crohn's disease according to the Vienna classification: disease location is a useful predictor of disease course. Eur J Gastroenterol Hepatol. 2006;18:255-261.

70. Chowers Y, Sela BA, Holland R, et al. Increased levels of homocysteine in patients with Crohn's disease are related to folate levels. Am J Gastroenterol. 2000;95:3498-3502.

71. Holland N, Harmatz P, Golden D, et al. Cytogenetic damage in blood lymphocytes and exfoliated epithelial cells of children with inflammatory bowel disease. Pediatr Res. 2007;61:209-214.

72. Heyman MB, Garnett EA, Shaikh N, et al. Folate concentrations in pediatric patients with newly diagnosed inflammatory bowel disease. Am J Clin Nutr. 2009;89:545-550.

73. Pan Y, Liu Y, Guo H, et al. Associations between folate and vitamin B12 levels and inflammatory bowel disease: a meta-analysis. Nutrients. 2017;9:382.

74. Solem CA, Loftus EV Jr, Tremaine WJ, et al. Correlation of C-reactive protein with clinical, endoscopic, histologic, and radiographic activity in inflammatory bowel disease. Inflamm Bowel Dis. 2005;11:707-712.
75. Fagan EA, Dyck RF, Maton PN, et al. Serum levels of C-reactive protein in Crohn's disease and ulcerative colitis. Eur J Clin Invest. 1982;12:351-359.

76. Vasseur F, Gower-Rousseau C, Vernier-Massouille G, et al. Nutritional status and growth in pediatric Crohn's disease: a population-based study. Am J Gastroenterol. 2010;105:1893-1900.

77. Fabisiak N, Fabisiak A, Watala $\mathrm{C}$, et al. Fat-soluble vitamin deficiencies and inflammatory bowel disease: systematic review and meta-analysis. $J$ Clin Gastroenterol. 2017;51:878-889.

78. Woodside JV, Young IS, Gilchrist SE, et al. Factors associated with serum/plasma concentrations of vitamins A, C, E and carotenoids in older people throughout Europe: the EUREYE study. Eur J Nutr. 2013;52:1493-1501.

79. Leiva E, Mujica V, Sepúlveda P, et al. High levels of iron status and oxidative stress in patients with metabolic syndrome. Biol Trace Elem Res. $2013 ; 151: 1-8$.

80. Trebble TM, Wootton SA, May A, et al. Essential fatty acid status in paediatric Crohn's disease: relationship with disease activity and nutritional status. Aliment Pharmacol Ther. 2003;18:433-442.

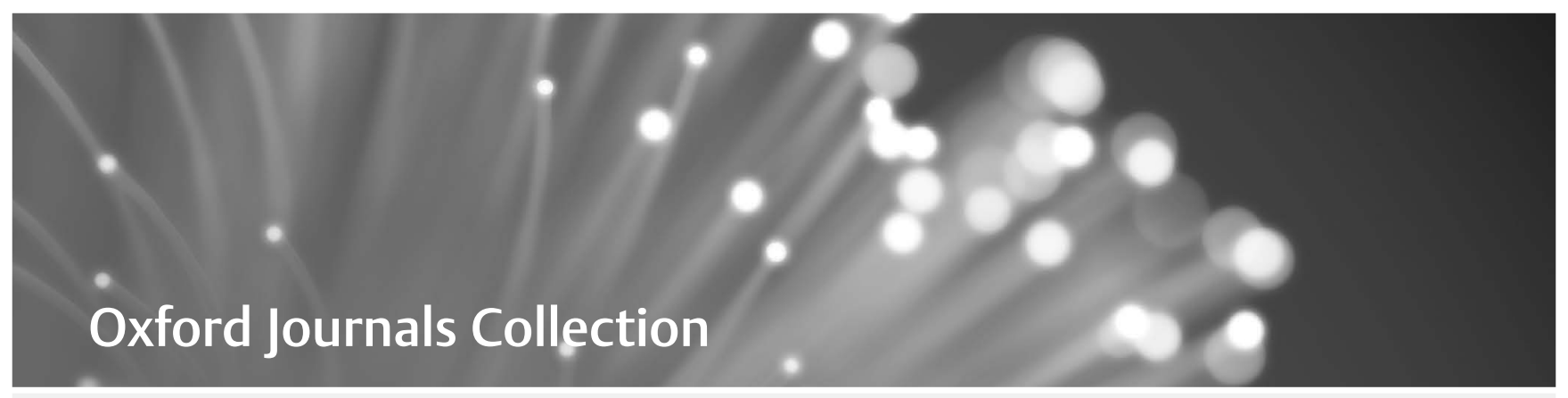

The Oxford Journals Collection includes highly cited, quality journals in the fields of Medicine, Life Sciences, Humanities, Law, Mathematics, Physical Sciences, and Social Sciences, offering access to content dating back to 1996.

Individual libraries and consortia can subscribe to the entire package, a subject subset, or a bespoke selection tailored to meet the needs of the library user.

Benefits for Libraries:

- Perpetual access to paid-for content

- Access available via IP address or remotely

- Mobile-optimized service

Pass this information on to your librarian and encourage them to visit academic.oup.com/journals/pages/librarians 